\title{
Acute Chloroform Ingestion Successfully Treated with Intravenously Administered $\mathrm{N}$-acetylcysteine
}

\author{
Damon M. Dell'Aglio • Mark E. Sutter • \\ Michael D. Schwartz • David D. Koch • D. A. Algren • \\ Brent W. Morgan
}

Published online: 15 June 2010

(C) The Author(s) 2010. This article is published with open access at Springerlink.com

\begin{abstract}
Chloroform, a halogenated hydrocarbon, causes central nervous system depression, cardiac arrhythmias, and hepatotoxicity. We describe a case of chloroform ingestion with a confirmatory serum level and resultant hepatotoxicity successfully treated with intravenously administered $\mathrm{N}$ acetylcysteine (NAC). A 19-year-old man attempting suicide ingested approximately $75 \mathrm{~mL}$ of chloroform. He was unresponsive and intubated upon arrival. Intravenously administered NAC was started after initial stabilization was complete. His vital signs were normal. Admission laboratory values revealed normal serum electrolytes, AST, ALT, PT, BUN, creatinine, and bilirubin. Serum ethanol level was $15 \mathrm{mg} / \mathrm{dL}$, and aspirin and acetaminophen were undetectable. The patient was extubated but developed liver function abnormalities with a peak AST of $224 \mathrm{IU} / \mathrm{L}$, ALT of $583 \mathrm{IU} /$ $\mathrm{L}$, and bilirubin level reaching $16.3 \mathrm{mg} / \mathrm{dL}$. NAC was continued through hospital day 6. Serum chloroform level obtained on admission was $91 \mu \mathrm{g} / \mathrm{mL}$. The patient was
\end{abstract}

D. M. Dell'Aglio • M. E. Sutter • M. D. Schwartz • D. D. Koch •

D. A. Algren · B. W. Morgan

Emory University,

Druid Hills, GA, USA

D. M. Dell'Aglio • M. E. Sutter • M. D. Schwartz - D. D. Koch •

D. A. Algren · B. W. Morgan

Georgia Poison Center,

Atlanta, GA, USA

M. E. Sutter $(\bowtie)$

Department of Emergency Medicine,

University of California, Davis,

PSSB 2100, 2315 Stockton Blvd,

Sacramento, CA 95818, USA

e-mail: mark.sutter@ucdmc.ucdavis.edu discharged to psychiatry without known sequelae and normal liver function tests. The average serum chloroform level in fatal cases of inhalational chloroform poisoning was $64 \mu \mathrm{g} /$ $\mathrm{mL}$, significantly lower than our patient. The toxicity is believed to be similar in both inhalation and ingestion routes of exposure, with mortality predominantly resulting from anoxia secondary to central nervous system depression. Hepatocellular toxicity is thought to result from free radical-induced oxidative damage. Previous reports describe survival after treatment with orally administered NAC, we report the first use of intravenously administered NAC for chloroform ingestion. Acute oral ingestion of chloroform is extremely rare. Our case illustrates that with appropriate supportive care, patients can recover from chloroform ingestion, and intravenously administered NAC may be of benefit in such cases.

Keywords Chloroform $\cdot N$-Acetylcysteine

\section{Background}

Chloroform, also known as trichloromethane, is one of many halogenated hydrocarbons. Chloroform was first discovered in 1831 and was used for general anesthesia by 1848 [1]. Toxicity from chloroform can include central nervous system depression, cardiac arrhythmias, hepatic injury, and hepatic cancer [1]. Most cases of chloroform toxicity are the result of inhalational exposures, and very few reports involve oral ingestions. Since this route of exposure is exceedingly rare, information regarding the clinical course and management dilemmas of chloroform ingestions is limited. We describe the successful treatment of an acute chloroform ingestion with intravenously administered $N$-acetylcysteine (NAC) despite having one 


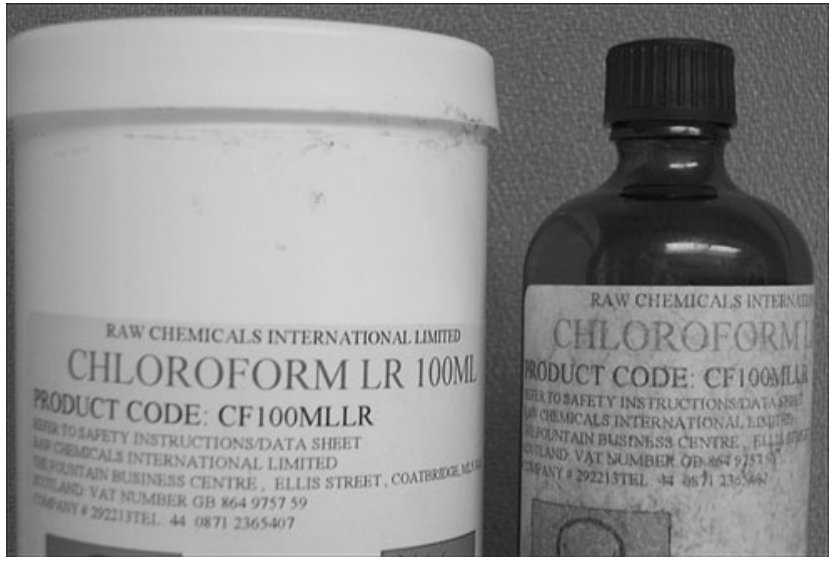

Fig. 1 A half-empty bottle of chloroform

of the highest reported serum chloroform levels in a survivor.

\section{Case Report}

A 19-year-old African-American man was found unconscious in his car with a suicide note and a half-empty bottle of chloroform he had ordered on the internet from overseas (Fig. 1). He was brought to the emergency department obtunded and required immediate endotracheal intubation and mechanical ventilation. It was later determined that he had drank about $75 \mathrm{~mL}$ of the chloroform prior to his being discovered. His initial vital signs included a heart rate of 75 beats/min and a blood pressure of 113/60 $\mathrm{mm} \mathrm{Hg}$; he was mechanically ventilated at a rate of 16 breaths/min with an oxygen saturation of $100 \%$ on $100 \% \mathrm{FIO}_{2}$. His physical examination was otherwise unremarkable. The patient had an ECG performed, which did not reveal any signs of ischemia with a QRS of $86 \mathrm{~ms}$ and QT of $408 \mathrm{~ms}$. Cardiac monitoring did not reveal ectopy. Blood drawn on arrival revealed a glucose of $135 \mathrm{mg} / \mathrm{dL}$, AST of $18 \mathrm{IU} / \mathrm{L}$, ALT of $10 \mathrm{IU} / \mathrm{L}$, total bilirubin of $1.3 \mathrm{mg} / \mathrm{dL}$, and direct bilirubin of $0.1 \mathrm{mg} / \mathrm{dL}$; PT was $13.6 \mathrm{~s}$ (INR 1.16) and had normal serum electrolytes, BUN, and creatinine. His admission serum ethanol concentration was $15 \mathrm{mg} / \mathrm{dL}$, and serum salicylate and acetaminophen concentrations were undetectable. His admission urine drug screen was only positive for opiates.

The poison center was notified by EMS upon finding the patient with bottle of chloroform, allowing us to evaluate the patient at bedside upon arrival in the emergency department. In light of chloroform's hepatotoxicity, therapy with NAC was recommended. The patient was treated with intravenously administered NAC $150 \mathrm{mg} / \mathrm{kg}$ over $1 \mathrm{~h}$, followed by $50 \mathrm{mg} / \mathrm{kg}$ over $4 \mathrm{~h}$, and then was started on an intravenous drip at a rate of $6.25 \mathrm{mg} \mathrm{kg}^{-1} \mathrm{~h}^{-1}$.

On the evening of the second hospital day, the patient had regained consciousness and was successfully extubated. Prior to extubation, the patient completed $21 \mathrm{~h}$ of intravenously administered NAC finishing the infusion the pharmacy had prepared. Because the patient was still intubated when the first infusion of NAC was completed, the decision was made to continue NAC at $6.25 \mathrm{mg} \mathrm{kg}^{-1} \mathrm{~h}^{-1}$. We had planned on stopping the intravenously administered NAC when the second pre-mixed infusion was finished; however, on hospital day 3, his total bilirubin began to rise although his AST and ALT remained normal. Since information on the

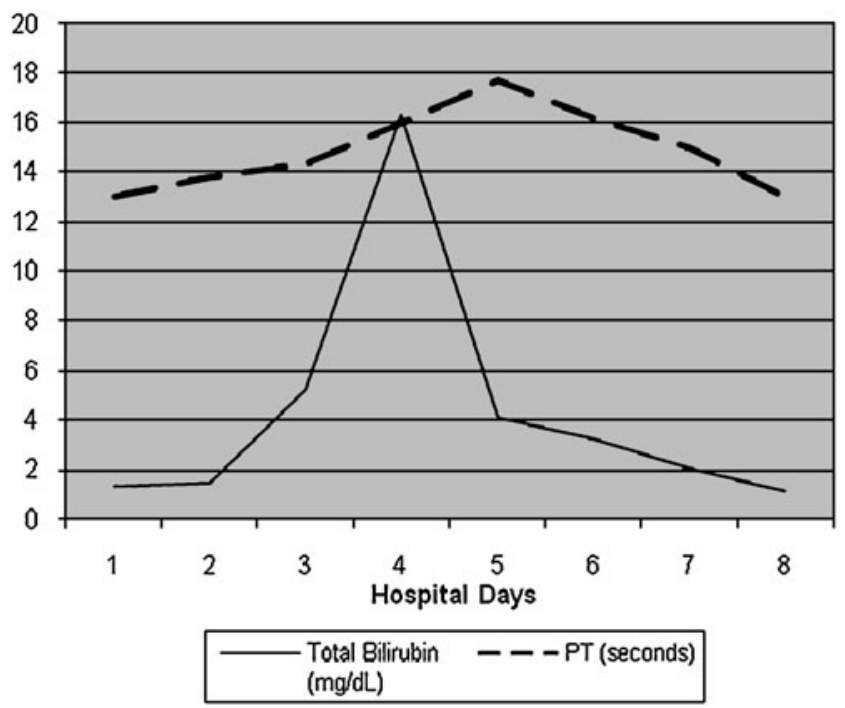

Fig. 2 Transaminase trends after ingestion

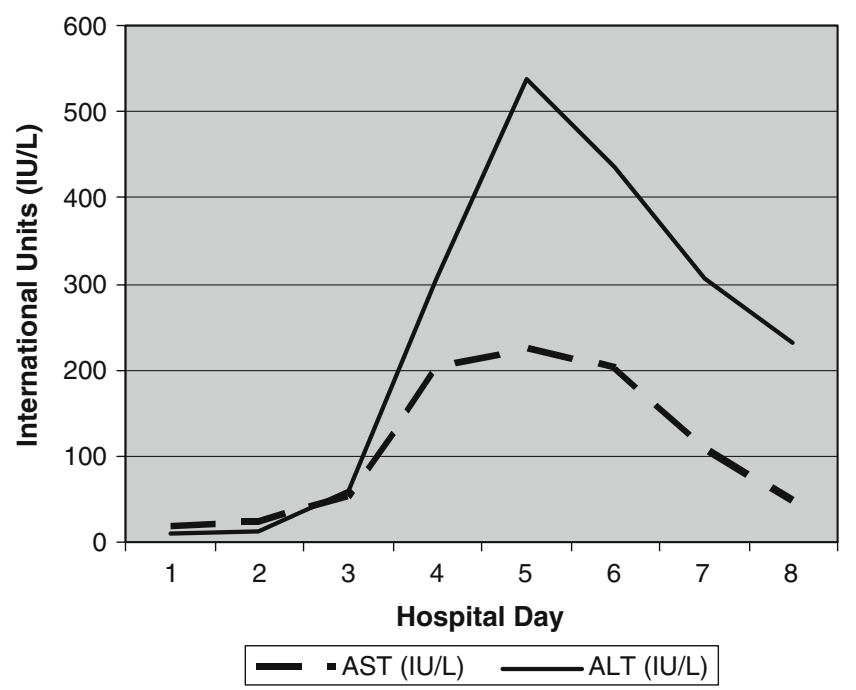

Fig. 3 Bilirubin and prothrombin time 
clinical course of chloroform ingestions is limited, we continued NAC therapy. On hospital day 4, his serum AST and ALT began to rise. His total serum bilirubin and PT both peaked on hospital day 4 at $16.3 \mathrm{mg} / \mathrm{dL}$ and $21.3 \mathrm{~s}$ (INR 2.25), respectively (Fig. 2). On hospital day 5, his AST and ALT had peaked at 224 and 583 IU/L, respectively (Fig. 3). At that time, his total serum bilirubin had fallen to $4.1 \mathrm{mg} /$ $\mathrm{dL}$, and his PT had declined to $17.7 \mathrm{~s}$ (INR 1.87). The following day, his serum bilirubin, AST, and ALT all began to decline, and intravenously administered NAC therapy was stopped. By hospital day 8 , the patient's AST had fallen to $47 \mathrm{IU} / \mathrm{L}$, his ALT had fallen to $231 \mathrm{IU} / \mathrm{L}$, his total serum bilirubin was $1.1 \mathrm{mg} / \mathrm{dL}$, and his PT had normalized. His BUN and creatinine remained normal throughout his hospital course. He was subsequently transferred to an inpatient psychiatric unit without observed permanent sequelae. His serum chloroform concentration on admission was later determined to be $91 \mu \mathrm{g} / \mathrm{mL}$.

\section{Discussion}

Like all halogenated hydrocarbons, chloroform exerts its anesthetic effects through activation of the $\mathrm{GABA}_{\mathrm{A}}$ receptor, causing an influx of chloride ions, hyperpolarizing the neuron and thereby clinically inducing sedation [2]. Most fatalities are believed to be the result of anoxia secondary to deep sedation and impairment of airway reflexes and respiratory drive [1,3]. Other observed effects of these agents can include sensitization of the myocardium to catecholamines, ventricular arrhythmias, and delayed hepatotoxicity resulting from free radical damage to the centrilobular hepatocytes $[1,3]$. Besides the above clinical findings, oral exposure to chloroform can also cause direct irritation of the oral, esophageal, and gastro-intestinal mucosa. Associated symptoms include chest pain, abdominal pain, nausea, and vomiting. If aspirated, chloroform can also cause symptoms of acute pneumonitis and acute lung injury [3].

Intravenously administered NAC therapy is commonly used for intubated patients in our institution. After the decision to use intravenously administered NAC, we had limited information on ingestions of chloroform to predict the duration of hepatotoxicity. Therefore, the NAC regimen was reassessed daily. His significant elevation of bilirubin on day 4 was surprising given that fact that his transaminases had just started to rise. The NAC regimen used in this case was the identical protocol used in acetaminophen toxicity. Due to continued abnormalities with his liver function testing, we continued the regimen of $6.25 \mathrm{mg} \mathrm{kg}^{-1} \mathrm{~h}^{-1}$ of intravenously administered NAC therapy through hospital day 6 until the hepatotoxicity had clearly improved.
Case reports of oral ingestions of chloroform have been previously described $[1,3-5]$. Other than the direct mucosal irritant effects described above, oral chloroform toxicity is believed similar to that of inhaled chloroform [1, 3, 4]. These previous case reports demonstrated average blood concentrations in fatal chloroform poisonings to have ranged between 33 and $64 \mu \mathrm{g} / \mathrm{mL}$. These levels are significantly lower than that of our patient who went on to have a complete recovery $[1,6]$.

The utilization of NAC for chloroform-induced hepatotoxicity has demonstrated successful outcomes in cases with mild hepatotoxicity [5, 7]. However, none of these previous cases utilized the intravenous formulation of NAC. Because chloroform is believed to cause hepatic damage by free radical injury and NAC is known to replete glutathione and scavenge free radicals, it is logical that both formulations of NAC may decrease hepatic injury secondary to chloroform exposure $[8,9]$.

A recent report describes a case of both chloroform and dichloromethane ingestion who survived without NAC therapy [10]. In this case, chloroform levels were not reported, but liver function tests peaked with an AST of 1,617 IU/L and ALT of 2,677 IU/L on days 4 and 5, respectively. Additionally, the total bilirubin peaked at $7 \mathrm{mg} / \mathrm{dL}$, and they report that liver function tests took 4 weeks to return within normal limits. Without knowing the chloroform level and further clinical information, it is difficult to quantify the effects of NAC therapy. However, our patient presented with a chloroform level well above reports of previous fatalities, and his AST and ALT peaked at only 224 and $583 \mathrm{IU} / \mathrm{L}$, respectively. Considering that NAC therapy has such low risk and high theoretical benefit, it should be considered for use in chloroform and other halogenated hydrocarbon-induced hepatotoxicity.

In summary, chloroform can cause injury resulting in central nervous system depression, respiratory depression, direct mucosal irritation, myocardial sensitization, and hepatotoxicity. Aggressive treatment with supportive care, with emphasis on protecting the airway and ventilation, as well as the use of NAC therapy to treat hepatic injury, can result in complete recovery even with significant elevated chloroform levels.

Open Access This article is distributed under the terms of the Creative Commons Attribution Noncommercial License which permits any noncommercial use, distribution, and reproduction in any medium, provided the original author(s) and source are credited.

\section{References}

1. Kohr RM (1990) Suicide by chloroform ingestion following self mutilation. Am J Forensic Med Pathol 11:324-328

2. Kaufman B, Griffel M (2006) Inhalational Anesthetics. In: Flomenbaum NE, Goldfrank LR, Hoffman RS, Howland MA, 
Lewin NA, Nelson LS (eds) Goldfrank's toxicologic emergencies, 8th edn. McGraw-Hill, New York, pp 1016-1023

3. Schroeder HG (1965) Acute and delayed chloroform poisoning. Brit J Anaesth 37:972

4. Hakim A, Jain AK, Jan R (1992) Chloroform ingestion causing toxic hepatitis. JAPI 40:477

5. Choi SH, Lee SW, Hong YS, Kim SJ, Moon SW, Moon JD (2006) Diagnostic radiopacity and hepatotoxicity following chloroform ingestion: a case report. Emerg Med J 23:394-395

6. Baselt RC, Cravey RH (1995) Disposition of toxic drugs and chemicals in man, 4th edn. Biomedical, Foster City, pp 146-148
7. Boyer E, Larson SC, Perrone J, De Roos F (1998) Limited hepatotoxicity following a massive chloroform ingestion treated with oral N-acetyl-cysteine. J Toxicol Clin Toxicol 36:440

8. Flanagan R, Meredith TJ (1991) Use of n-acetyl-cysteine in clinical toxicology. Am J Med 91:131-139

9. Chyka P, Butler A, Holliman B, Herman M (2000) Utility of acetylcysteine in treatment of poisonings and adverse drug reactions. Drug Saf 2:123-148

10. Kim H (2008) A case of acute toxic hepatitis after suicidal chloroform and dichloromethane ingestion. Am J Emerg Med 26 (9):1073.e3-1073.e6 